\title{
Aloperin improves liver non-alcoholic steatohepatitis in vitro and in vivo
}

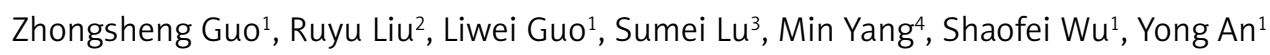

\begin{abstract}
${ }^{1}$ Department of Infection Diseases and Liver Diseases, The First Affiliated Hospital of Shandong First Medical University (Shandong Provincial Qianfoshan Hospital), Jinan, China

2Department of Hepatology, Beijing Ditan Hospital Capital Medical University, Beijing, China

${ }^{3} \mathrm{PCR}$ laboratory, The First Affiliated Hospital of Shandong First Medical University (Shandong Provincial Qianfoshan Hospital), Jinan, China

${ }^{4}$ Department of Clinical Pathology, The First Affiliated Hospital of Shandong First Medical University (Shandong Provincial Qianfoshan Hospital), Jinan, China
\end{abstract}

Submitted: 6 January 2020

Accepted: 6 February 2020

Arch Med Sci

DOI: https://doi.org/10.5114/aoms.2020.95629

Copyright $\odot 2020$ Termedia \& Banach

\section{Abstract}

Introduction: The aim of this work is to investigate the inhibitory effect of aloperin (Alo) on hepatocyte apoptosis in non-alcoholic fatty liver disease, and the underlying mechanism.

Material and methods: Rats in the Alo groups were fed a high-fat + high-sugar diet for eight weeks and then treated with low-, moderate-, and high-dose Alo for another eight weeks via gavage. Oxidative stress indices were tested by a colourimetric method, and pathological changes were observed by haematoxylin-eosin staining. Apoptosis was detected by TUNEL staining. TLR4, TRIF, and NF- $\kappa B(p 65)$ mRNA and protein expressions were detected by RT-qPCR, Western blot assay and immunohistochemistry. In the in vitro study, L02 cells were treated with FFA (free fatty acid) for $24 \mathrm{~h}$ to establish a non-alcoholic steatohepatitis (NASH) model. Inhibition of cell proliferation was measured by the MTT method, and cell apoptosis was evaluated by flow cytometry. Finally, the nuclear import volume of NF- $\kappa \mathrm{B}(\mathrm{p} 65)$ was evaluated by cellular immunofluorescence. Results: Cell apoptosis significantly decreased in the Alo-treatment groups in a dose-dependent manner $(p<0.05)$. TLR4, TRIF, and NF-KB(p65) expression in the Alo-treatment groups was significantly downregulated compared with model group $(p<0.05)$. The cell proliferation rate significantly increased, cell apoptosis significantly decreased $(p<0.05)$, and the TLR4/ TRIF/NF- $\kappa B$ pathway was significantly inhibited $(p<0.05)$ in the Alo-treatment groups. The nuclear import volume of NF- $\mathrm{KB}(\mathrm{p} 65)$ in the Alo-treatment groups was significantly decreased compared with that in the model group in a dose-dependent manger $(p<0.05)$.

Conclusions: Alo could improve NASH via the TLR4/TRIF/NF- $\kappa B$ pathway.

Key words: aloperin, non-alcoholic steatohepatitis, TLR4/TRIF/NF- $\kappa B$, cell apoptosis.

\section{Introduction}

Non-alcoholic fatty liver disease (NAFLD) is a metabolic syndrome commonly seen in clinical practice. As living standards in China continue to improve, the dietary structures and lifestyles of the country's citizens has become increasingly westernised and the incidence rate of

\author{
Corresponding author: \\ Yong An \\ Department of \\ Infection Diseases and \\ Liver Diseases \\ The First Affiliated Hospital \\ of Shandong First \\ Medical University \\ Shandong Provincial \\ Qianfoshan Hospital \\ Jinan, China \\ E-mail: anyong0106@163. \\ com
}


NAFLD has grown. Non-alcoholic steatohepatitis (NASH), one of the two subtypes of NAFLD, may eventually progress to liver cirrhosis and cancer [1]. Unfortunately, because the number of NAFLD cases in China has gradually increased, the number of cases of liver cirrhosis has also risen. Therefore, exploration of the pathological mechanism of NASH and development of approaches to prevent its occurrence are important research hotspots. The most commonly recognised theories of the pathogenesis of NAFLD include the "two-hit" mechanism. In this mechanism, the first hit induces fat accumulation. Then, under the effects of cytokines produced during stress, pathogenic factors, and activation of hepatic stellate cells, the second hit occurs, leading to inflammation, apoptosis, and fibrosis of the liver [2-4]. This mechanism indicates that regulating the inflammatory reaction may significantly reduce, delay, or even reverse the incidence of fatty liver. Thus, regulation of the inflammatory reaction is an important target in NASH drug research.

Aloperin (Alo), an alkaloid extracted from the TCM Sophora alopecuroides, has anti-inflammation, anti-tumour, and anti-infection effects [5]. Research shows that Alo could efficiently inhibit the apoptosis caused by various forms of inflammation [6-9]. In the present research, the hepato-protective activity of Alo towards NASH and its possible mechanism were explored by assessing the influence of the alkaloid on the expression of Toll-like receptor (TLR) 4 and relevant proteins in NASH cells and liver of rats.

\section{Material and methods}

Fifty clean, healthy, adult male Sprague-Dawley rats weighing 180-220 g were provided by the Laboratory Animal Centre in Kunming Medical University (License No. SYXK (dian)2011-0004) and fed adaptively for 2 weeks in the laboratory. Rats in the normal group were fed normal fodder for 16 weeks. Rats in the model and Alo groups were continuously fed a high-fat + high-sugar diet $(8 \%$ normal fodder, $2 \%$ cholesterol, and $10 \%$ lard oil) for 16 weeks. After feeding for 12 weeks, 5,25 , and $50 \mathrm{mg} / \mathrm{kg} \cdot \mathrm{d}$ Alo (Ningxia Yanchi Pharmaceutical Factory) was administered to rats in the Alo-L, Alo-M, and Alo-H groups, respectively, by gavage for 8 weeks. After feeding for 16 weeks, the rats were anaesthetised intraperitoneally and sacrificed using $2 \%$ Nembutal. Blood samples were collected, and the liver was rapidly excised. Liver samples were obtained from the same portion of the bulk organ from each rat and fixed with $4 \%$ paraformaldehyde. The remaining livers were stored in a refrigerator at $-80^{\circ} \mathrm{C}$.

\section{Preparation and observation of hepatic tissue specimens}

Hepatic tissues were fixed with $4 \%$ paraformaldehyde and prepared for paraffin sectioning. The sections were stained with haematoxylin-eosin, and changes in the morphology of hepatic tissues were observed under an optical microscope at $200 \times$ magnification.

\section{TUNEL testing}

After paraffin embedding, tissue slices (thickness, $5 \mu \mathrm{m}$ ) were dewaxed in xylene and hydrated using an ethanol gradient. A dUTP terminal transferase kit was used to examine cell apoptosis in liver tissues and counted through a high-power field of $400 x$. Photographs of the tissue slices were obtained by a microscope.

\section{Immunohistochemistry assay}

Hepatic tissue specimens were embedded in paraffin to prepare slices and perform tissue antigen repair with dewaxing. The slices were rinsed first with distilled water and then with PBS three times. Next, the slices were incubated at room temperature with hydrogen peroxide for 5-10 min to eliminate the activity of endogenous peroxidase. The slices were rinsed once more with distilled water, immersed in PBS, and sealed with normal goat serum at a volume fraction of $5-6 \%$. The specimens were incubated at room temperature for $30 \mathrm{~min}$, applied with a working solution of primary antibodies (TLR4 $1: 1000$; TRIF $1: 1000$; NF-кB 1 : 1000), and then incubated for $1-2 \mathrm{~h}$ at $37^{\circ} \mathrm{C}$ or in a refrigerator at $4^{\circ} \mathrm{C}$ overnight. After incubation, the specimens were rinsed thrice with PBS for 3 min each time, dripped with the appropriate anti-working solution marked with biotin, and incubated at $37^{\circ} \mathrm{C}$ for $15 \mathrm{~min}$. Thereafter, the specimens were rinsed thrice with PBS for 3 min each time, stained with $D A B$, rinsed thoroughly with tap water, re-dyed, dehydrated, transparentised, and sealed. The results were observed under an optical microscope at $200 \times$ magnification.

\section{RT-qPCR}

Rat liver tissues and total DNA in cells were extracted according to the instructions of an RNA extraction kit and reverse-transcribed according to a reverse transcription $k$ it. The reaction conditions were as follows: $37^{\circ} \mathrm{C}(15 \mathrm{~min} \times 1 \mathrm{cycle})$ and $85^{\circ} \mathrm{C}$ ( $5 \mathrm{~s} \times 1 \mathrm{cycle}$ ). The RT products were stored at $4^{\circ} \mathrm{C}$. Then, $2 \mu$ of the RT products was blended with the reagents of a real-time PCR kit (total volume, $20 \mu \mathrm{l})$ for PCR amplification under the following reaction conditions: $95^{\circ} \mathrm{C}(30 \mathrm{~s}, 1 \mathrm{cycle})$ and $\left(95^{\circ} \mathrm{C}\right.$ $\times 5 \mathrm{~s}, 60^{\circ} \mathrm{C} \times 34 \mathrm{~s}$ ) for a total of 40 cycles. The rel- 
ative contents of the target genes were calculated using the $2^{-\triangle \Delta C T}$ method. The primer sequences used were as follows: TLR4: F: 5'-CTGCATAGAGGTAGTTCCT-3'; R: 5'-TCCAGCCACTGAAGTTCTGA-3'; TRIF: F: 5'-AGATCAGCCAGTCGCCCACTCT-3'; R: 5'GTCAGGTTCTTCGCAGCCTTCAG-5'; NF-кB): F: 5-ACGATCTGTTTCCCCTCATC-3'; R: 5'-TGCTTCTCTCCCCAGGAATA-3'; $\beta$-actin: F: 5'-AGTCTGTGTGGATTGGTGGC-3'; R: 5'-AGAAAGGGTGTAAAACGGAGC-3'.

\section{Cell culture}

Cryopreserved L02 cells were rapidly thawed at $37^{\circ} \mathrm{C}$, centrifuged at $1000 \mathrm{rpm}$ for $5 \mathrm{~min}$, and washed twice with DMEM culture solution. The cells were then resuspended in DMEM basal culture medium and centrifuged once more. Next, the cells were added with DMEM complete medium and cultured with $5 \% \mathrm{CO}_{2}$ at $37^{\circ} \mathrm{C}$.

\section{Establishment of the NASH cell model}

The cell concentration was adjusted to $1 \times$ $10^{5} / \mathrm{ml}$, and cells were inoculated into the wells of a 96 -well culture plate $(100 \mu \mathrm{l} /$ well). The cells were incubated for $24 \mathrm{~h}$ in $5 \% \mathrm{CO}_{2}$ until $80 \%$ adhesion was achieved. The cells were stimulated with $500 \mu \mathrm{mol} / \mathrm{L}$ FFA (determined by the results of trial tests) for $24 \mathrm{~h}$ to establish the NASH cell model.

\section{Cell grouping}

L02 cells were divided into the normal, model, and Alo-treatment groups (including low [Alo-L)-, moderate (Alo-M)-, and high (Alo-H)-dose groups). Cells in the model and Alo-treatment groups were used to construct a NASH cell model. LO2 cells in the Alo-L, Alo- $\mathrm{M}$, and Alo-H treatment groups were treated with 5,25 , and $50 \mathrm{ml} / \mathrm{l}$ Alo, respectively, for $72 \mathrm{~h}$ for follow-up experiments.

\section{Examination of apoptosis by flow cytometry}

L02 cells in each group were digested with pancreatin and then collected. The cells were rinsed twice with PBS and centrifuged at $1000 \mathrm{rpm}$ and $4^{\circ} \mathrm{C}$ for $5 \mathrm{~min}$. The cells were added with $500 \mu \mathrm{l}$ of binding buffer for suspension and then treated with $5 \mu \mathrm{l}$ of annexin V-FITC and $5 \mu \mathrm{l}$ of propidium iodide. The reagents were allowed to react for $10 \mathrm{~min}$ at room temperature in the dark. Finally, the cells were examined using a flow cytometer. This experiment was repeated three times.

\section{Assessment of NF- $\mathrm{B}(\mathrm{p} 65)$ nuclear import by cell immunofluorescence}

LO2 cells in the logarithmic phase were obtained from each group, the serum was carefully eliminated with PBS, and the cells were rinsed. The cells were fixed with $70 \%$ methanol solution at $4{ }^{\circ} \mathrm{C}$ for $30 \mathrm{~min}$, incubated for $15 \mathrm{~min}$ with $0.5 \%$ Triton $\mathrm{X}-100$ to remove the cytomembrane, and sealed with $5 \%$ goat serum for $1 \mathrm{~h}$. Next, the cells were treated with the rabbit anti-human monoclonal antibody of NF- $\mathrm{B}(\mathrm{p} 65)$ (dilution, 1 : 200) and incubated overnight at $4^{\circ} \mathrm{C}$. The samples were rinsed thrice with PBST for 10 min each time, treated with FTTC-labelled fluorescence secondary antibodies (dilution, $1: 200$ ), and rinsed thrice with PBST for 10 min each time. The cell nucleus was dyed with $10 \mu \mathrm{g} / \mathrm{ml} \mathrm{DAPI}$, and the resulting fluorescence intensity was examined by using Image-Pro Plus6.0 software.

\section{Western blot}

The cells were placed in an ice bath, cracked in RIPA lysate for $30 \mathrm{~min}$, centrifuged at 15,000 rpm for $20 \mathrm{~min}$ at $4^{\circ} \mathrm{C}$, and then stored in the supernatant at $-80^{\circ} \mathrm{C}$. A BCA kit was applied to measure protein concentrations. An equivalent amount of protein was loaded onto $10 \%$ SDS-polyacrylamide gel for electrophoresis, transferred to a PVDF membrane, and then sealed for $1 \mathrm{~h}$ at room temperature with 5\% BSA. The cells were incubated overnight at $4^{\circ} \mathrm{C}$ with antibodies for TLR4 (1:100), TRIF

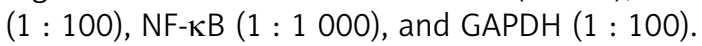
The cells were then incubated with the corresponding secondary antibodies $(1: 10,000)$ at room temperature for $1 \mathrm{~h}$. Finally, the cells were stained using an ECL kit and processed using Image-J to analyse grey levels.

\section{Statistical analysis}

The experiment data are presented as mean \pm SD, and SPSS version 21.0 was employed for data analysis. One-way ANOVA was used if the data reflected a normal distribution and even variance. The rank sum test was used if the data reflected a non-normal distribution or uneven variance. For all analyses, $p<0.05$ indicated that the results were of statistical significance.

\section{Results}

Influence of Alo on pathological changes in the hepatic tissues of NASH rats

Tissues in the normal group revealed hepatic cells with a normal aligned structure. The cellular boundary was clear, and the nucleus was round and clear. No fat degeneration, inflammation, or necrosis was seen. Hepatic tissues in the model group showed severe injury. A large amount of hepatic tissues revealed swelling and hydropic degeneration. Circular lipid droplets of different sizes, indicating fat degeneration of hepat- 
ic tissues, could be observed in the cytoplasm. Squeezing of the nucleus to the margin, inflammatory cell infiltration in the lobule and portal areas, and point- or strip-like necrosis of hepatic cells were also noted. Tissues in the Alo-L, Alo-M, and Alo-H groups showed obvious reductions in hepatic injury compared with those in the model group. The hepatic tissues of the Alo-treatment groups showed mild fatty lesions, and the sinusoidal structure of hepatic cells was quite clear. Lipid droplets in the cytoplasm of hepatic cells greatly decreased or disappeared completely (Figure 1).

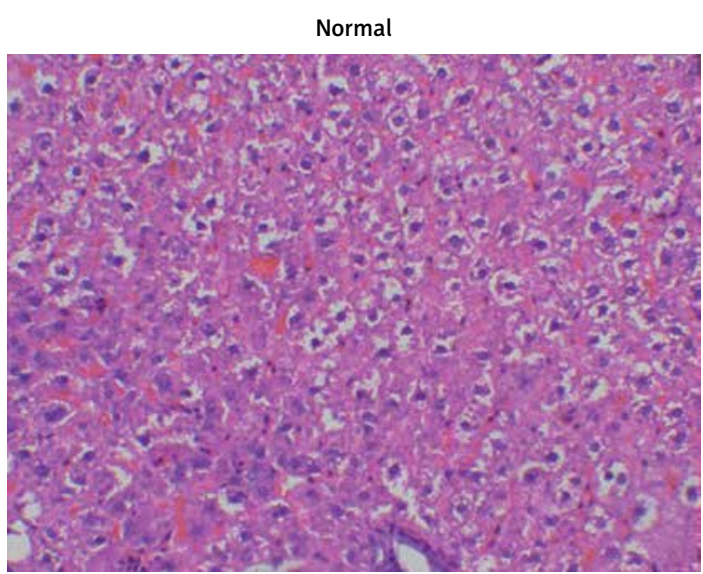

Alo-L

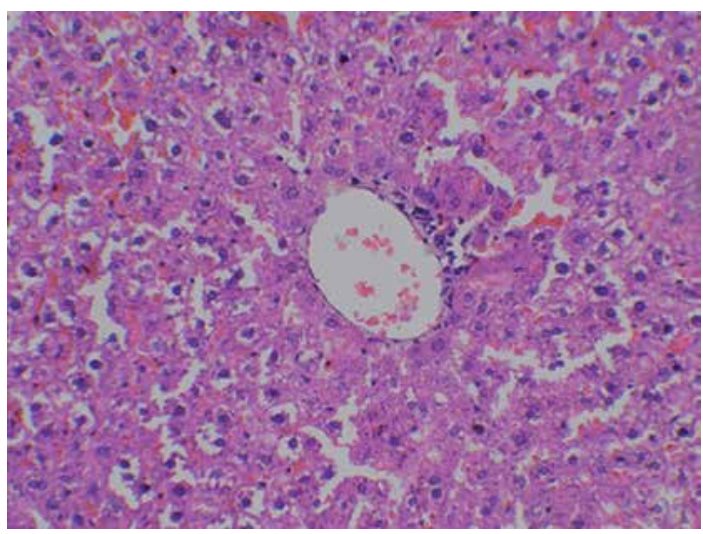

Alo-H

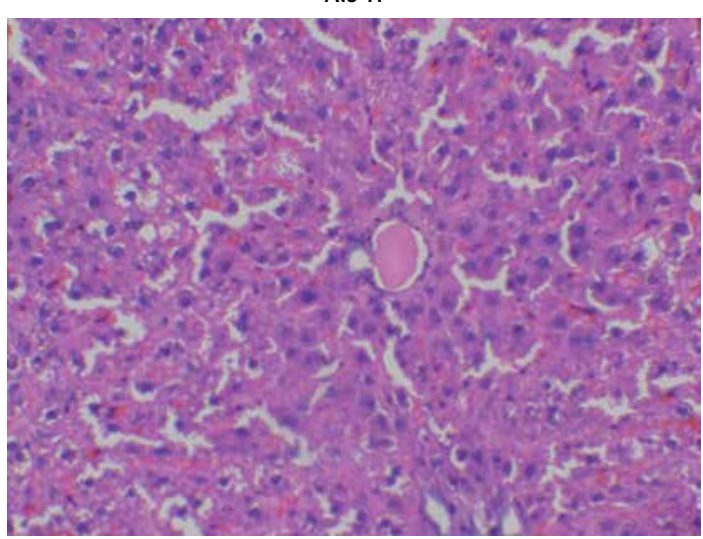

Effects of Alo on the apoptosis of cells in the hepatic tissues of NASH rats and related mRNA

TUNEL testing revealed that the apoptosis rate in the model group was remarkably increased compared with that in the normal group $(p<0.001$, Figure $2 \mathrm{~A}$ ). After Alo treatment, the apoptosis rate in the Alo-L, Alo-M, and Alo-H groups was significantly reduced compared with that in the model group $(p<0.05, p<0.01$, and $p<0.001$, respectively; Figure 2 A). Significant differences were observed between the Alo-L, Alo-M, and Alo-H groups ( $p<0.05$ and $p<0.01$; Figure 2 A). RT-qPCR testing indicated

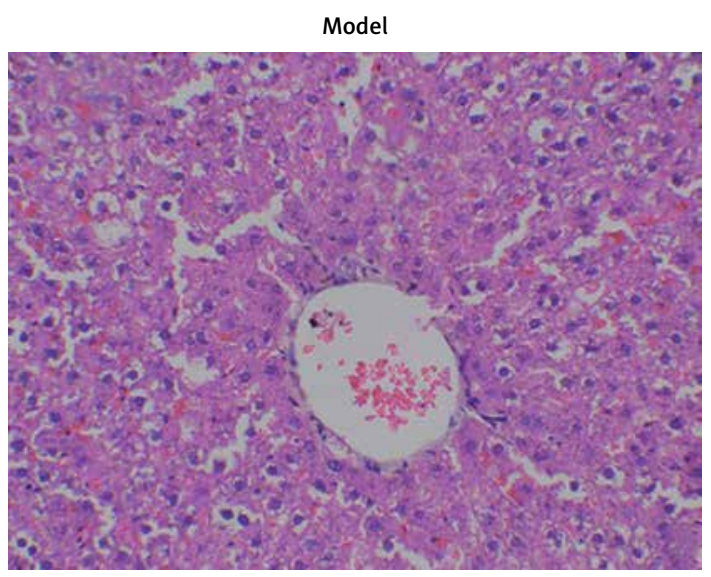

Alo-M

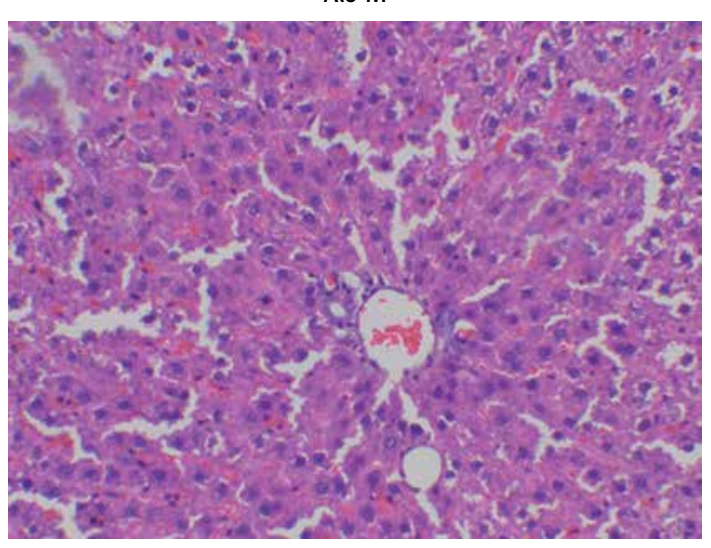

Figure 1. Determination of pathological differences amongst groups by haematoxylin-eosin staining (200x). Normal: Rats fed a normal diet. Model: Rats fed a high-fat diet. Alo-L: Rats treated with $5 \mathrm{mg} /$ $\mathrm{kg}$-day Alo after feeding for 12 weeks. Alo-M: Rats treated with $25 \mathrm{mg} / \mathrm{kg}$.day Alo after feeding for 12 weeks. Alo-H: Rats treated with $50 \mathrm{mg} / \mathrm{kg}$.day Alo after feeding for 12 weeks 
that the expression levels of TLR4, TRIF, and NF- $\kappa B$ genes in the model group were greatly enhanced compared with those in the normal group $(p<$ 0.001; Figure 2 B). After Alo treatment, the expression levels of TLR4, TRIF, and NF- $\kappa B(p 65)$ genes in the Alo-L, Alo-M, and Alo-H groups significantly decreased compared with those in the model group ( $p<0.05$ and $p<0.01$; Figure 2 B). Significant dif-

\section{A}

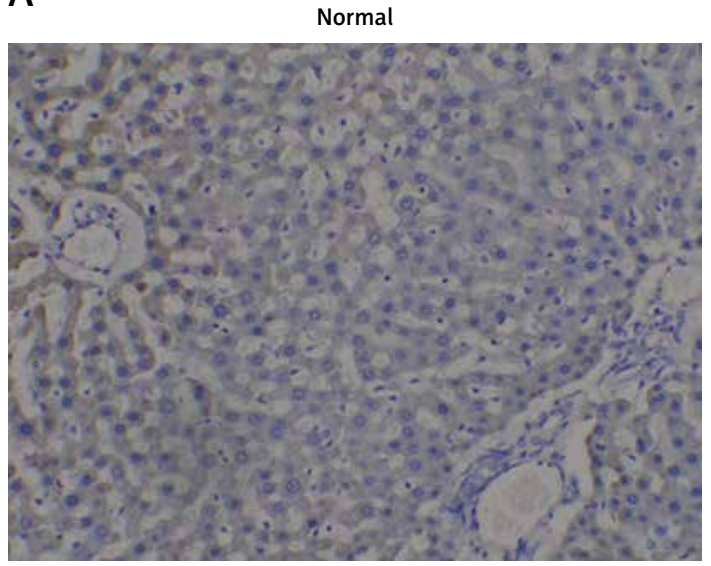

Alo-L

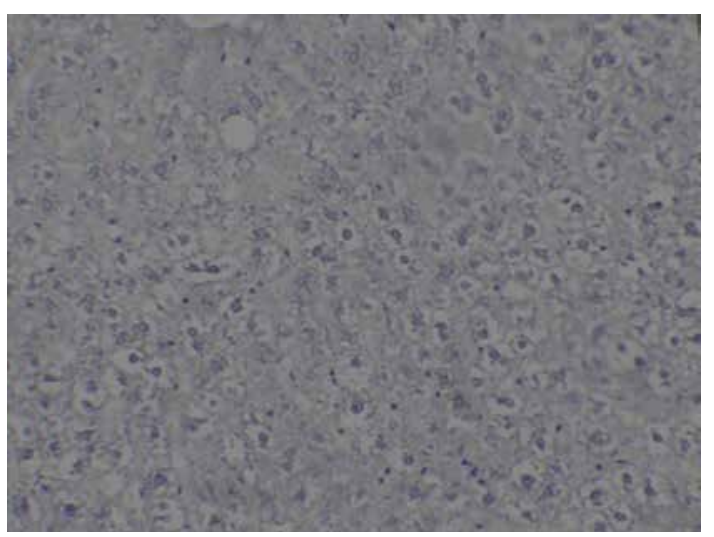

Alo-H

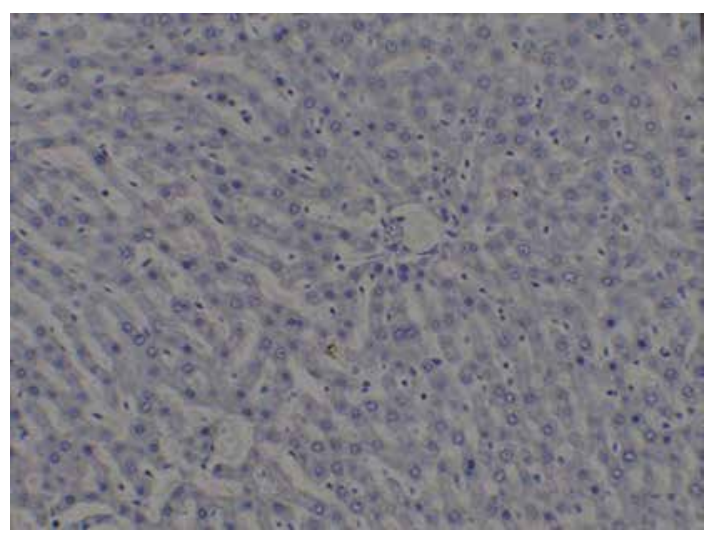

ferences were found between the Alo-L, Alo-M, and Alo-H groups ( $p<0.05$ and $p<0.01$; Figure $2 \mathrm{~B}$ ).

\section{The influence of Alo on the expression of related proteins}

Immunohistochemistry (IHC) examination showed that the protein expression levels of TLR4, TRIF,

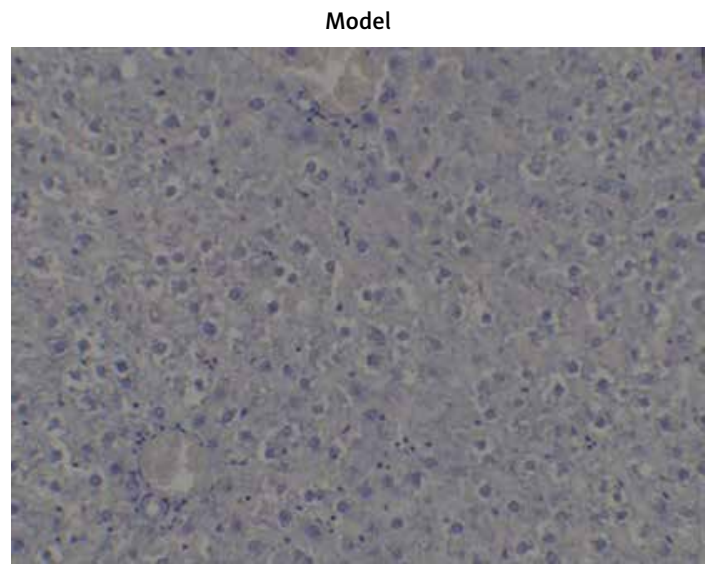

Alo-M
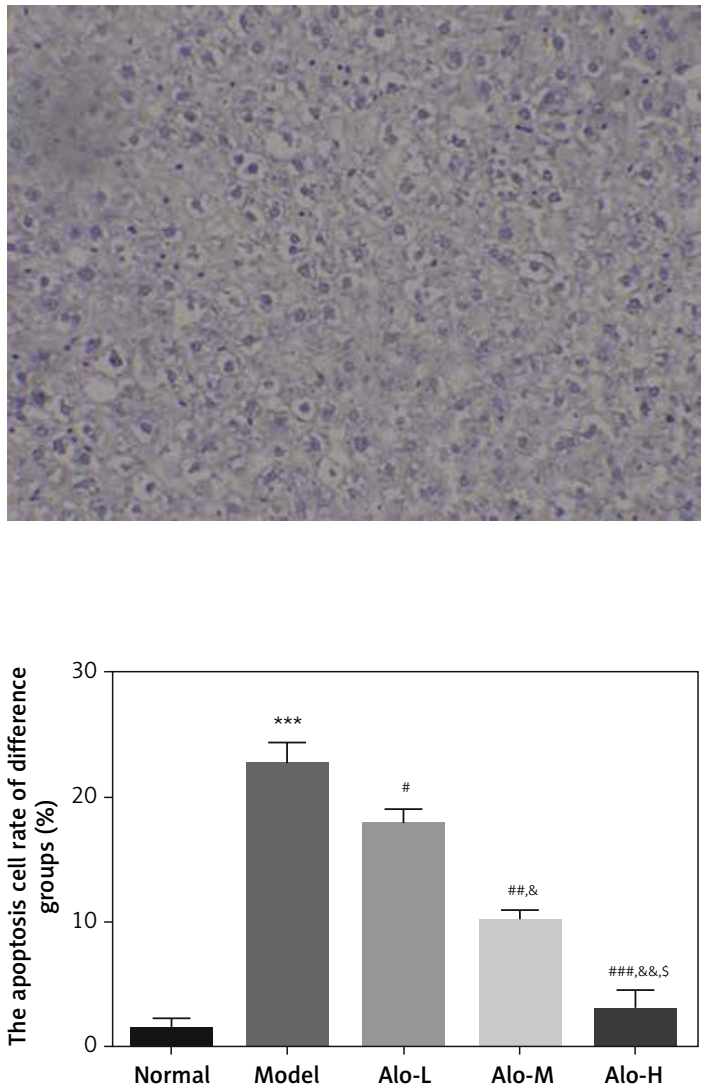

Figure 2. Determination of hepatic cell apoptosis by TUNEL assay and relative mRNA expression by RT-qPCR assay. Normal: Rats fed a normal diet. Model: Rats fed a high-fat diet. Alo-L: Rats treated with $5 \mathrm{mg} / \mathrm{kg}$. day Alo after feeding for 12 weeks. Alo-M: Rats treated with $25 \mathrm{mg} / \mathrm{kg}$-day Alo after feeding for 12 weeks. Alo-H: Rats treated with $50 \mathrm{mg} / \mathrm{kg}$. day Alo after feeding for 12 weeks. A - Determination of hepatic cell apoptosis by TUNEL assay (200x)

${ }^{* * *} p<0.001$, compared with the normal group; ${ }^{*} p<0.05,{ }^{* \#} p<0.01,{ }^{\# \#} p<0.001$, compared with the model group; ${ }^{*} p<0.05$, ${ }^{\&} \& p<0.01$, compared with the Alo-L group; ${ }^{5} p<0.05$, compared with the Alo-M group. 

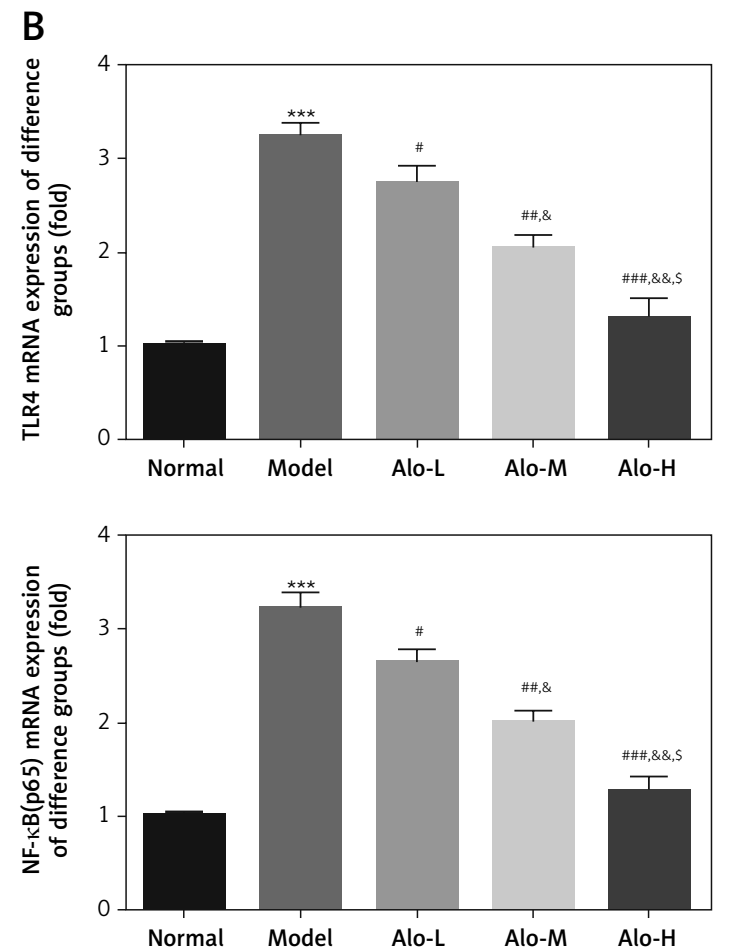

and NF- $\mathrm{KB}(\mathrm{p} 65)$ in the model group are greatly increased compared with those in the normal group ( $p<0.001$, Figure 3). After Alo treatment, the expression levels of TLR4, TRIF, and NF- $\mathrm{KB}(\mathrm{p} 65)$ genes in the Alo-L, Alo-M, and Alo-H groups greatly decreased compared with those in the model group ( $p<0.05$ and $p<0.01$; Figure 3). Significant differences were noted amongst the Alo-L, Alo-M, and Alo-H groups ( $p<0.05$ and $p<0.01$; Figure 3 ).

\section{Influence of Alo on cell apoptosis in each group}

Flow cytometry demonstrated that the apoptosis rate in the model group was greatly increased compared with that in the normal group $(p<$ 0.001; Figure 4). After Alo treatment, the apoptosis rates of hepatic tissues in the Alo-L, Alo-M, and Alo-H groups were significantly decreased compared with that in the model group $(p<0.05, p<$ 0.01 , and $p<0.001$; Figure 4). Significant differences were noted amongst the Alo-L, Alo-M, and Alo-H groups ( $p<0.05$ and $p<0.01$; Figure 4$)$.

\section{The influence of Alo on cell-associated} genes and proteins in each group

RT-qPCR and Western blot examination indicated that the expression levels of TLR4, TRIF, and NF$\kappa \mathrm{B}(\mathrm{p} 65)$ genes and proteins in the model group were greatly improved compared with those in the normal group ( $p<0.001$; Figures 5 A, B). After Alo treatment, the expression levels of TLR4, TRIF, and $\mathrm{NF}-\kappa \mathrm{B}(\mathrm{p} 65)$ genes and proteins in the Alo-L, Alo-M, and Alo-H groups were greatly reduced compared

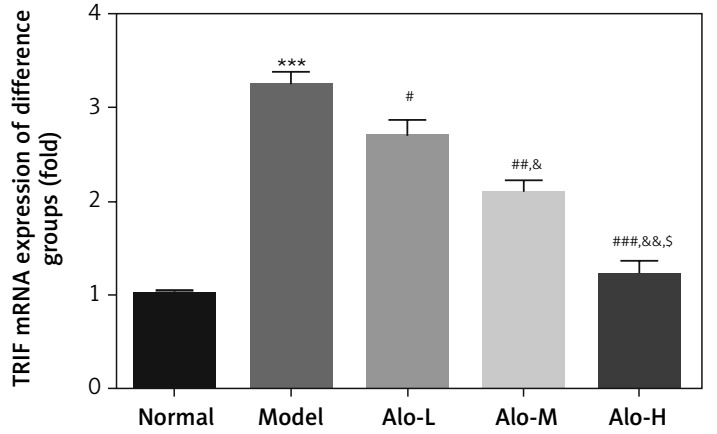

Figure 2. Cont. B - Determination of TLR4, TRIF, and NF- $\kappa B(p 65)$ mRNA expression by RT-qPCR assay

${ }^{* * *} P<0.001$, compared with the normal group; ${ }^{*} p<0.05$, \#\# $p<0.01$, \#\# $p<0.001$, compared with the model group ${ }^{*} p<0.05,{ }^{\&} \& p<0.01$, compared with the Alo-L group; ${ }^{s} p<0.05$, compared with the Alo-M group.

with those in the model group ( $p<0.05$ and $p<$ 0.01 ; Figures $5 \mathrm{~A}, \mathrm{~B})$. Significant differences were observed beween the Alo-L, Alo-M, and Alo-H groups ( $p<0.05$ and $p<0.01$; Figures $5 \mathrm{~A}, \mathrm{~B})$.

\section{The effects of Alo on the nuclear import volume of $\mathrm{NF}-\kappa \mathrm{B}(\mathrm{p} 65)$ protein}

Cell immunofluorescence examination showed that the nuclear import volume of $\mathrm{NF}-\mathrm{\kappa B}(\mathrm{p} 65)$ in the model group was greatly increased compared with that in the normal group ( $p<0.001$; Figure 6). After Alo treatment, the nuclear import volume of NF- $\mathrm{B}$ (p65) in the Alo-L, Alo-M, and Alo-H groups significantly decreased compared with that in the model group ( $p<0.05$ and $p<0.01$; Figure 6). Significant differences were observed amongst the Alo-L, Alo-M, and Alo-H groups ( $p<0.05$ and $p<$ 0.01 ; Figure 6).

\section{Discussion}

TLR, a lipopolysaccharide receptor discovered in recent years, includes 10 members (TLR1-10). Amongst these receptors, TLR2 and TLR4 are the major family members. TLR2 mainly induces inflammatory reactions caused by bacterial exotoxins, whilst TLR4 mainly induces inflammatory reactions caused by bacterial endotoxins. Once TLR4 is activated through cascade reactions, a series of signal molecules are recruited in the intracellular Toll/IL-1R (TIR) structural domain, activating nuclear factor (NF)- $\kappa$ B and causing an inflammatory factor cascade reaction of core pro-inflammatory factors, which were mainly tumour necrosis factor $\alpha$ 
A

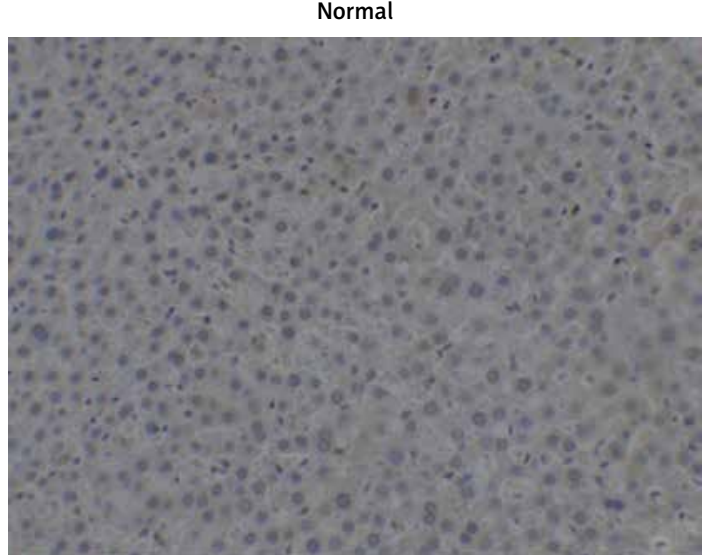

Alo-L

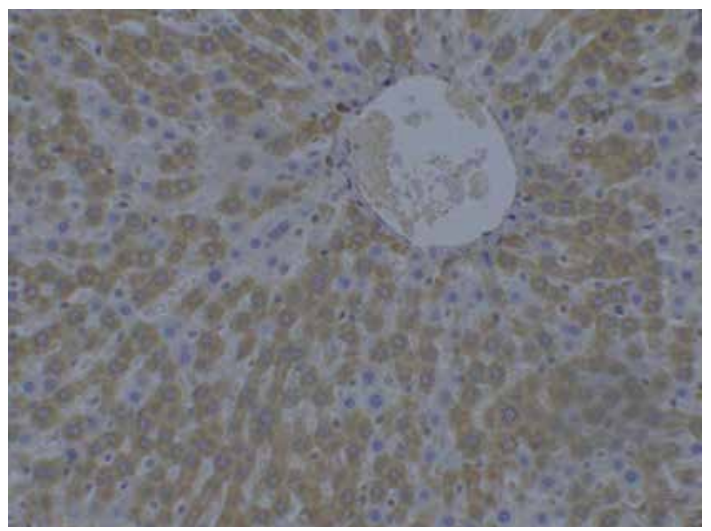

Alo-H

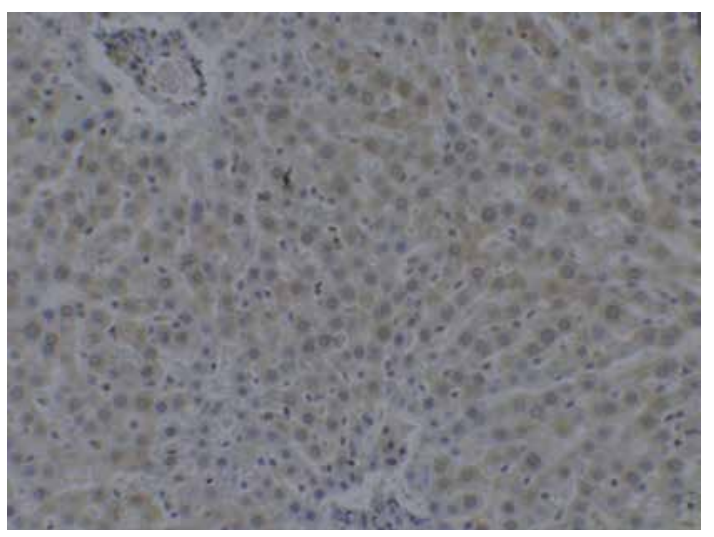

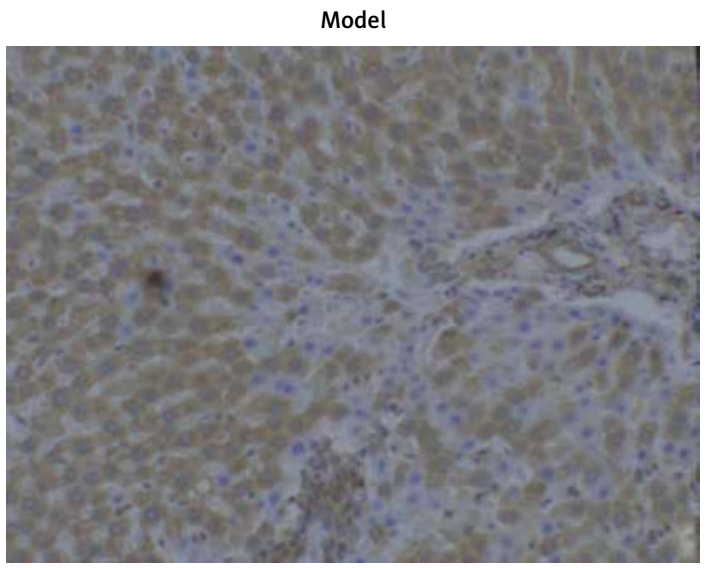

Alo-M
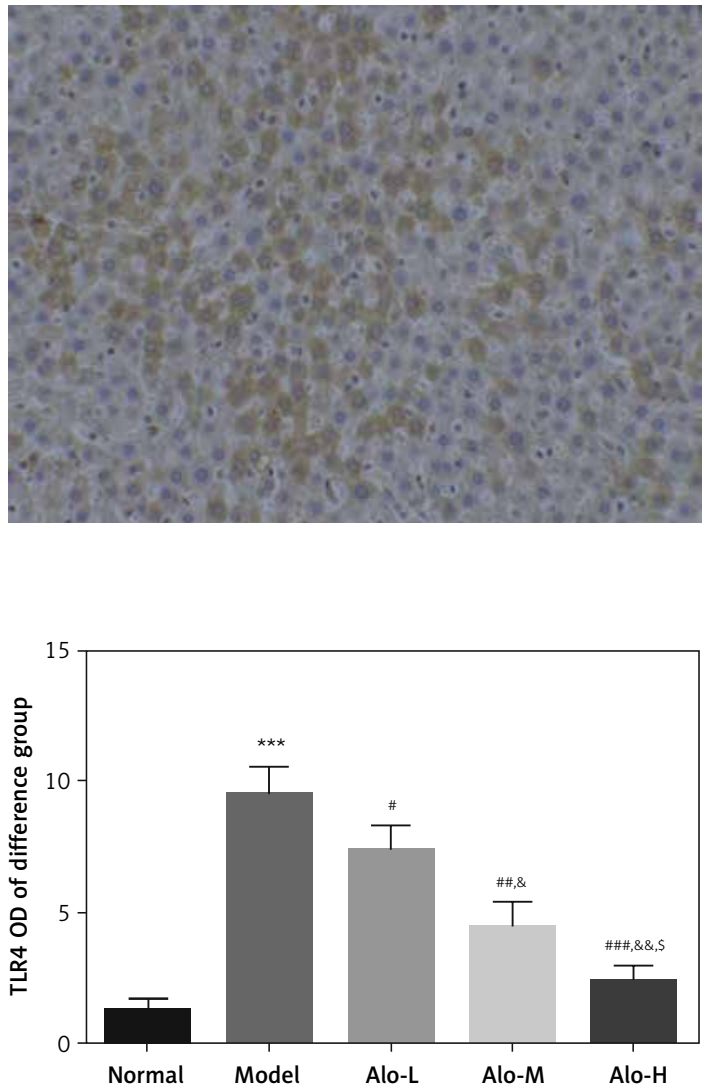

Figure 3. Determination of TLR4, TRIF, and NF- $\mathrm{BB}(\mathrm{p} 65)$ protein expression by immunohistochemistry (IHC) assay. A - Determination of TLR4 protein expression in different groups by IHC assay (200x)

${ }^{* * *} p<0.001$, compared with the normal group; ${ }^{*} p<0.05,{ }^{\# \#} p<0.01,{ }^{\# \#} p<0.001$, compared with the model group; ${ }^{*} p<0.05$, ${ }^{\&} \& p<0.01$, compared with the Alo-L group; ${ }^{5} p<0.05$, compared with the Alo-M group.

(TNF- $\alpha$ ), forming a second hit force and leading to organism damage [10-12]. TNF- $\alpha$ plays a major role in its signal transduction pathway, and TNF- $\alpha$ could inhibit the lipid activity. Recent research shows that high concentrations of TNF- $\alpha$ could decrease lipolysis in peripheral tissues and promote the binding and agglomeration of hepatic tissues to triacylglycerol. Deposition of surplus lipid, especially triacylglycerol, in the liver is a pre- condition for NAFLD formation and development. Previous studies indicated that elevation of serum endotoxin levels is positively correlated with TNF- $\alpha$ levels [13-15].

Alo, one of the major alkaloids extracted from S. alopecuroides, is characterised by easy extraction and low toxicity. Relevant research has verified that Alo could efficiently improve inflammatory reactions caused by various diseases [16-18]. In this research, 
B

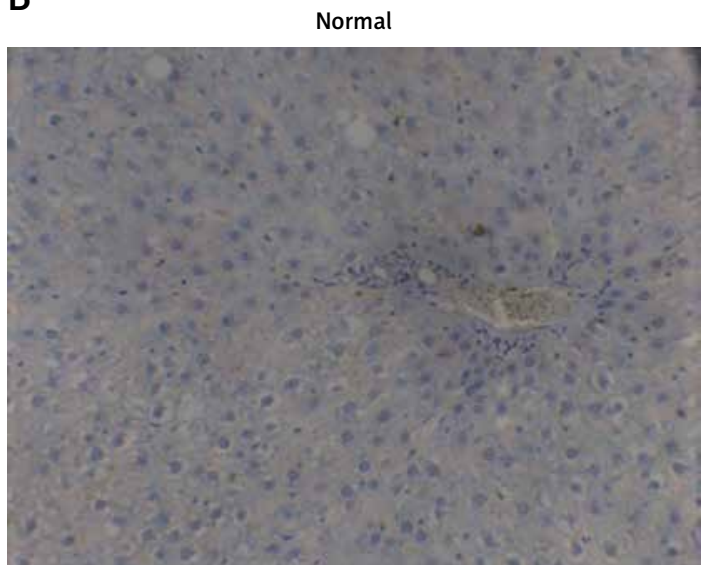

Alo-L

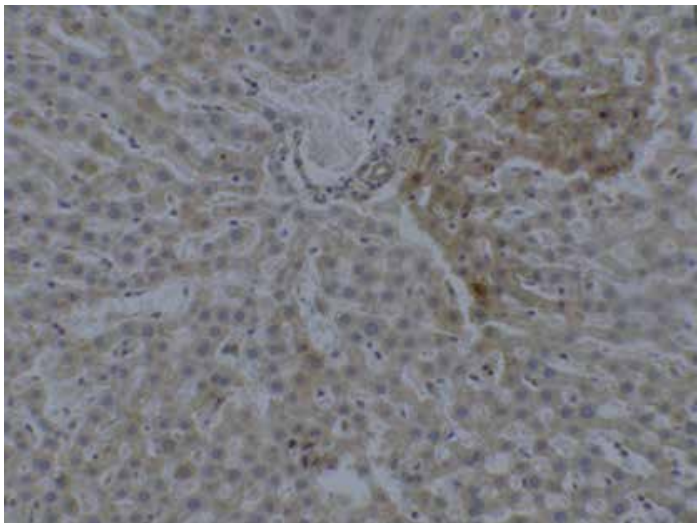

Alo-H

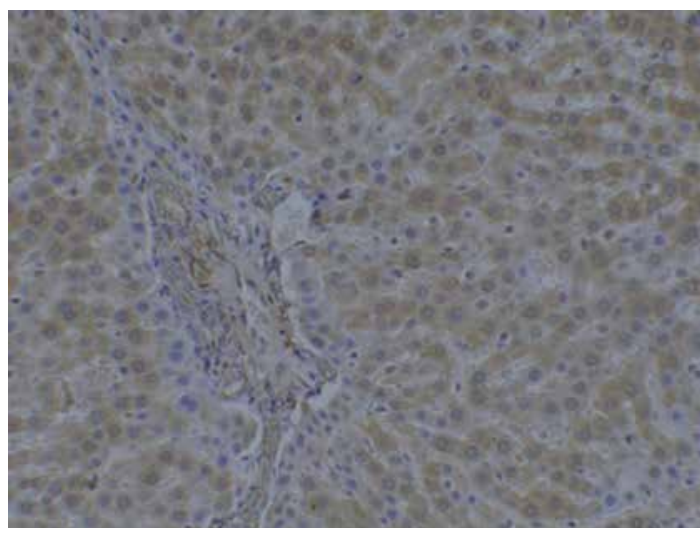

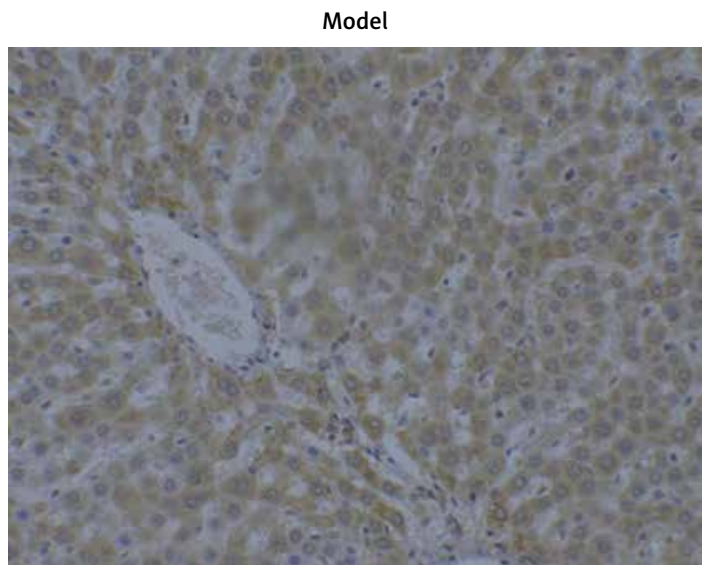

Alo-M
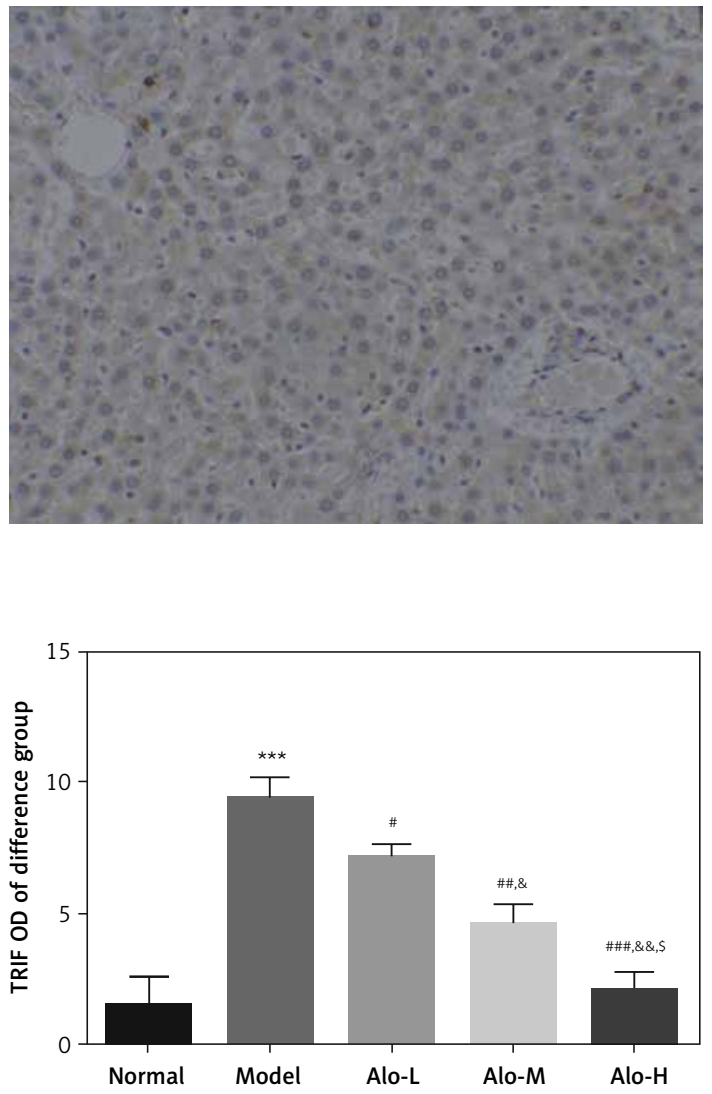

Figure 3. Cont. B - Determination of TRIF protein expression in different groups by IHC assay $(200 \times)$

${ }^{\star * *} p<0.001$, compared with the normal group; ${ }^{*} p<0.05,{ }^{\# \# p}<0.01$, \#\# $p<0.001$, compared with the model group; ${ }^{*} p<0.05$,

$\& \& p<0.01$, compared with the Alo-L group; ${ }^{s} p<0.05$, compared with the Alo-M group.

we confirmed that Alo could effectively facilitate the pathological status of hepatic tissues in NAFLD rats through in in vivo and in vitro experiments. TUNEL staining and flow cytometry showed that Alo could significantly improve the apoptosis caused by NAFLD in animal and cell models. To explore the related mechanism, we examined genes and proteins relevant to the TLR4/RTIF/NF- $\mathrm{KB}$ signal pathway in NAFLD animal and cell models and found that the expression levels of TLR4, RTIF, and NF- $\mathrm{KB}(\mathrm{p} 65)$ genes and proteins were greatly elevated. However, after Alo treatment, the expression levels of TLR4, RTIF, and NF- $\mathrm{KB}(\mathrm{p} 65)$ genes and proteins declined remarkably in a dose-dependent manner. Cell IHC testing showed that the nuclear import volume of NF- $\kappa \mathrm{B}(\mathrm{p} 65)$ protein was significantly improved in the NAFLD cell model, which means increases in this protein could promote inflammation in NAFLD and thus lead to apoptosis. Interestingly, Alo treatment greatly improved this situation. 
C

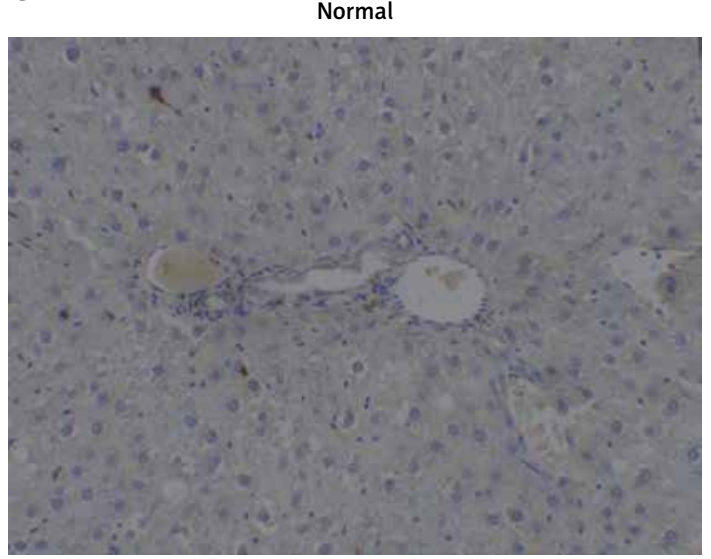

Alo-L

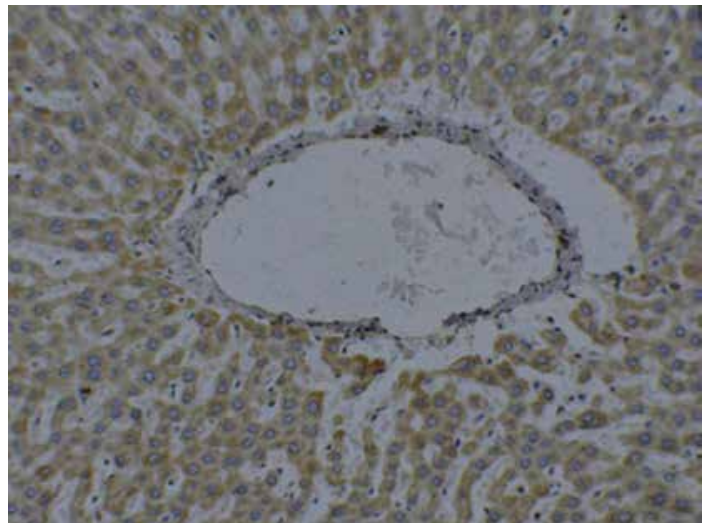

Alo-H

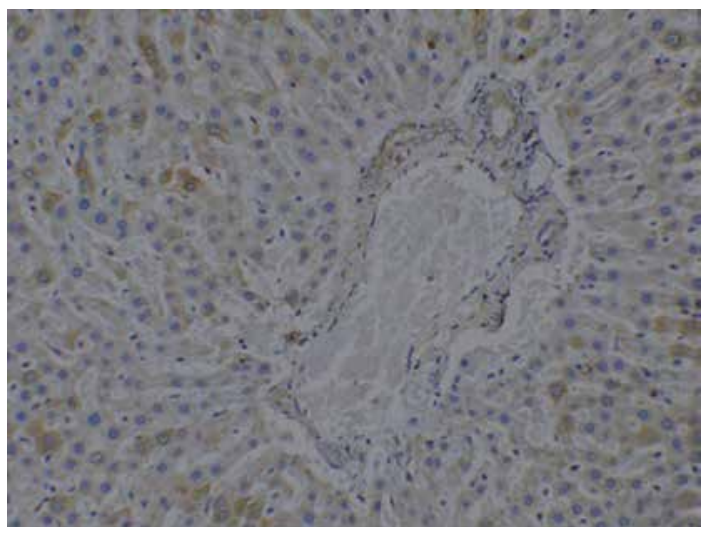

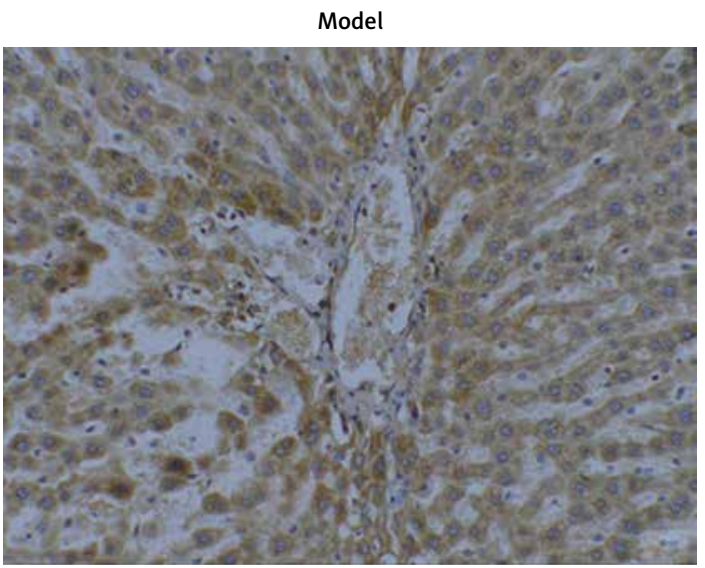

Alo-M
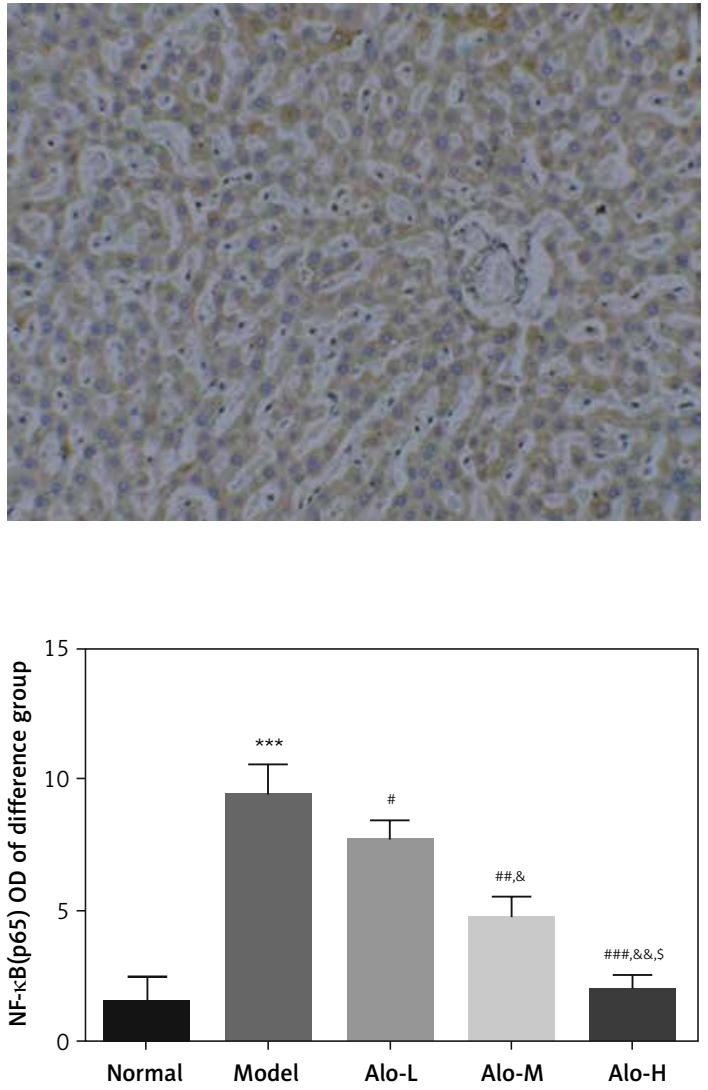

Figure 3. Cont. $\mathrm{C}$ - Determination of NF- $\mathrm{KB}(\mathrm{p} 65)$ protein expression in different groups by IHC assay $(200 \times)$

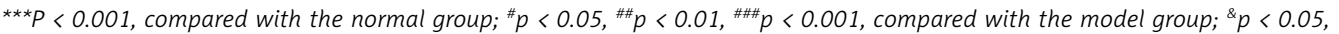

\&\& $p<0.01$, compared with the Alo-L group; ${ }^{s} p<0.05$, compared with the Alo-M group.

$\mathrm{NF}-\kappa \mathrm{B}$, a heterodimer consisting of P50 and P65 subgroups, exists in the cytoplasm in an inactive form and could transform into nuclear transcription factor within the nucleus after activation. The protein complex was found to inhibit the apoptosis induced by TNF-Ct in 1996. Activated NF- $\kappa B$ can obstruct the apoptosis of multiple cells, and NF- $\kappa B$ lacking P50 is able to maintain its anti-apoptosis capability. The effect of this protein complex is believed to involve the inhibition of caspase- 8 activation by anti-apoptosis proteins (TRAFI, TRAF2, c-IAPI, and c-IAP2) through caspases reaction $[19,20]$. In addition, NF- $\kappa B(p 65)$ could exert anti-apoptotic effects by inducing the expression of anti-apoptosis genes [21].

In conclusion, TRL4-induced inflammatory reactions may be one of the mechanisms of NAFLD injury. The protective role of Alo in the liver could be related to reductions in TRL4 expression and inhibition of the inflammatory reaction. 

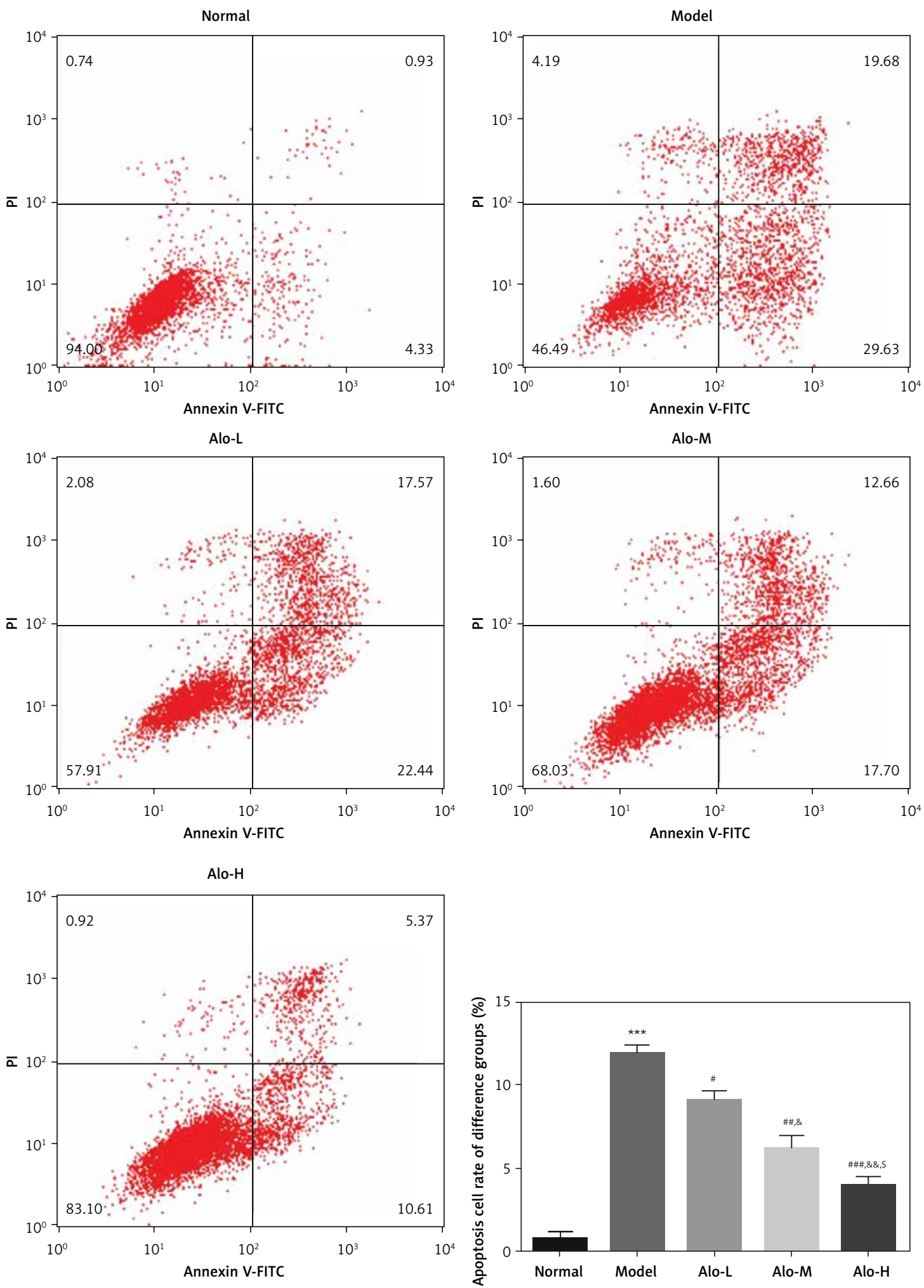

Figure 4. Determination of cell apoptosis in different groups by flow cytometry. Normal: L02 cells subjected to normal treatment. Model: L02 cells treated with $500 \mu \mathrm{mol} / /$ FFA as the NASH cell model. Alo-L: LO2 cells based on the NASH cell model treated with $5 \mathrm{ml} / \mathrm{I}$ Alo. Alo-M: LO2 cells based on the NASH cell model treated with $25 \mathrm{ml} / \mathrm{l}$ Alo. Alo-H: LO2 cells based on the NASH cell model treated with $50 \mathrm{ml} / / \mathrm{Alo}$

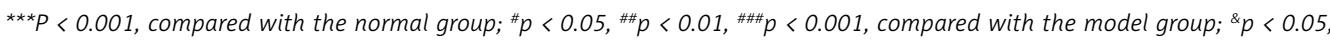
$\therefore \& p<0.01$, compared with the Alo-L group; ${ }^{s} p<0.05$, compared with the Alo-M group. 
A
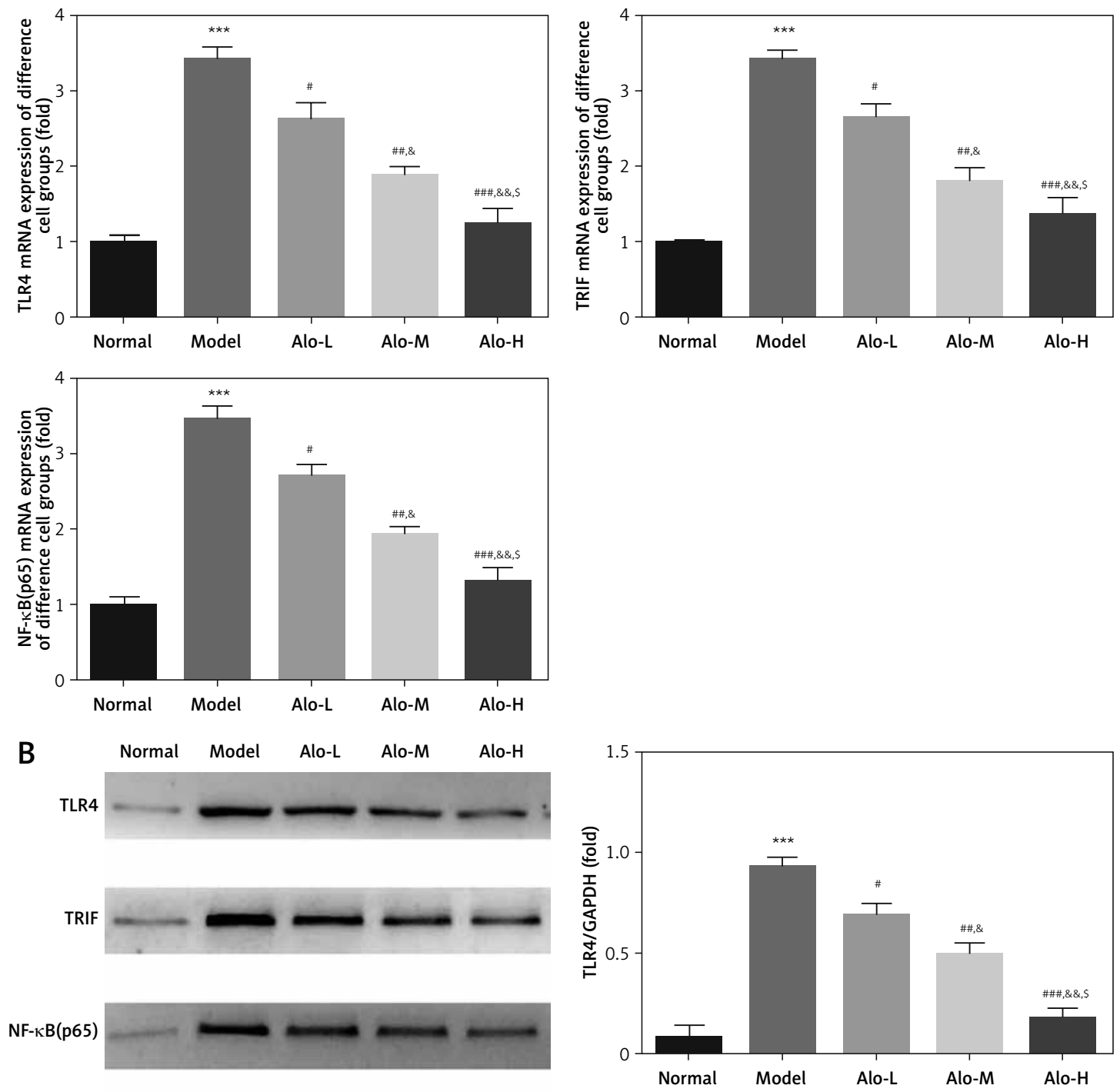

GAPDH
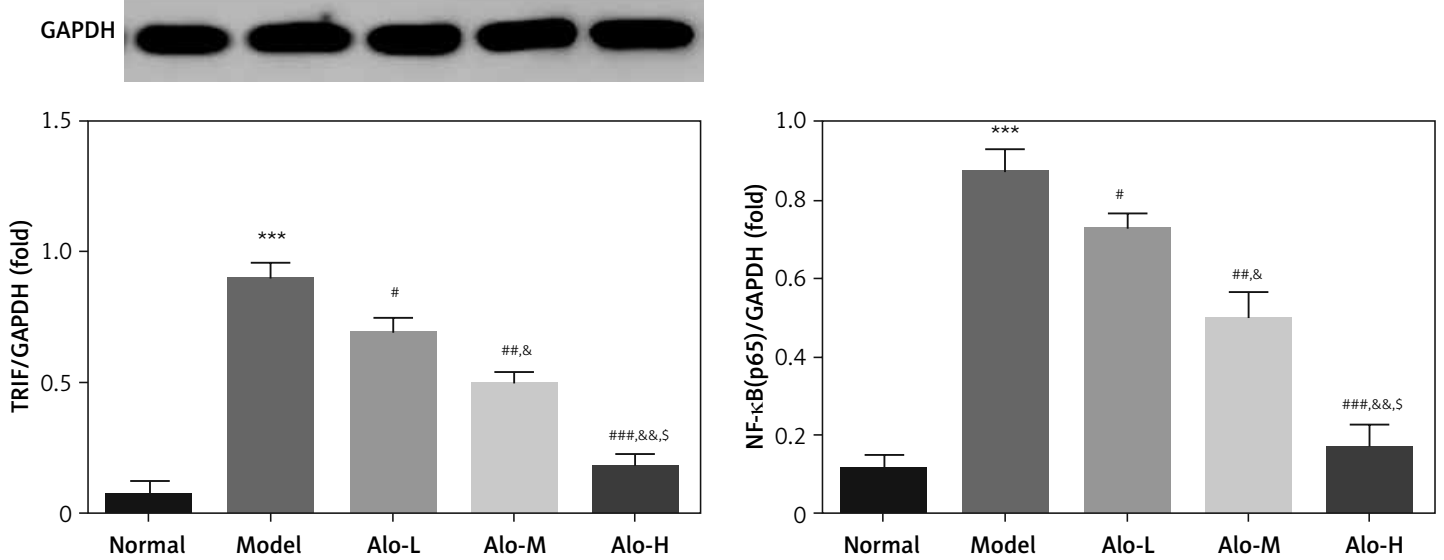

Figure 5. Determination of TLR4, TRIF, and NF- $\mathrm{kB}(\mathrm{p} 65)$ mRNA expression by RT-qPCR and protein expression by Western blot (WB) assay. Normal: L02 cells subjected to normal treatment. Model: L02 cells treated with $500 \mu \mathrm{mol} / \mathrm{I}$ FFA as the NASH cell model. Alo-L: LO2 cells based on the NASH cell model treated with $5 \mathrm{ml} / \mathrm{l}$ Alo. Alo-M: LO2 cells based on the NASH cell model treated with $25 \mathrm{ml} / \mathrm{l}$ Alo. Alo-H: LO2 cells based on the NASH cell model treated with $50 \mathrm{ml} / \mathrm{l}$ Alo. A - Determination of TLR4, TRIF, and NF- $\kappa B$ mRNA expression by RT-qPCR assay. B - Determination of TLR4, TRIF, and NF-אB protein expression by WB assay

${ }^{* *} p<0.001$, compared with the normal group; ${ }^{*} p<0.05,{ }^{\# \# p} p<0.01$, ${ }^{\# \# *} p<0.001$, compared with the model group; ${ }^{*} p<0.05$, \&\& $p<0.01$, compared with the Alo-L group; ${ }^{s} p<0.05$, compared with the Alo-M group. 

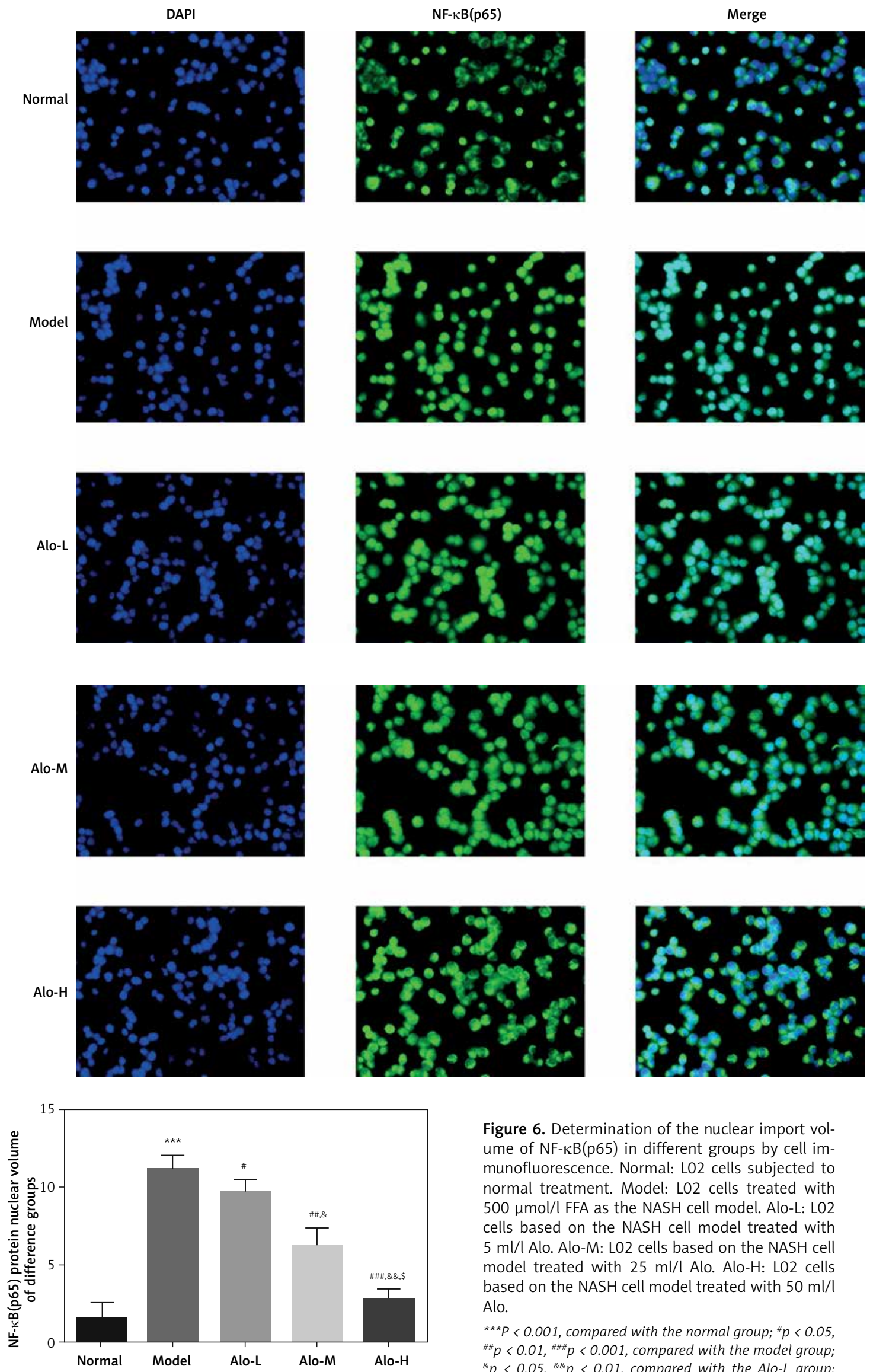

Figure 6. Determination of the nuclear import volume of NF-kB(p65) in different groups by cell immunofluorescence. Normal: L02 cells subjected to normal treatment. Model: LO2 cells treated with $500 \mu \mathrm{mol} / \mathrm{I} \mathrm{FFA}$ as the NASH cell model. Alo-L: L02 cells based on the NASH cell model treated with $5 \mathrm{ml} / \mathrm{I}$ Alo. Alo-M: LO2 cells based on the NASH cell model treated with $25 \mathrm{ml} / \mathrm{l}$ Alo. Alo-H: LO2 cells based on the NASH cell model treated with $50 \mathrm{ml} / \mathrm{l}$ Alo.

${ }^{* * *} p<0.001$, compared with the normal group: $* p<0.05$, $\# p<0.01, \# \# p<0.001$, compared with the model group ${ }^{\&} p<0.05$, \&\& $p<0.01$, compared with the Alo-L group $s_{p}<0.05$, compared with the Alo- $M$ group. 


\section{Acknowledgments}

This work was funded by the $12^{\text {th }} 5$-year S\&T Program of Shandong Province P.R. China. (Grant nos: 2014ZZCX02201) and Key R\&D Project of Shandong Province P.R. China (grant no. 2019GSF108129).

\section{Conflict of interest}

The authors declare no conflict of interest.

\section{References}

1. Carr RM, Oranu A, Khungar V. Nonalcoholic fatty liver disease-pathophysiology and management. Gastroenterol Clin North Am 2016; 45: 639-52.

2. Beyaz MO, Ugurlucan M, Oztas DM, et al. Evaluation of the relationship between plaque formation leading to symptomatic carotid artery stenosis and cytomegalovirus by investigating the virus DNA. Arch Med Sci Atheroscler Dis 2019; 4: e19-24.

3. Shen X, Guo H, XU J, Wang J. Inhibition of IncRNA HULC improves hepatic fibrosis and hepatocyte apoptosis by inhibiting the MAPK signaling pathway in rats with nonalcoholic fatty liver disease. J Cell Physiol 2019; 234: 18169-79.

4. Bassler J, Ducatman A, Elliott M, et al. Environmental perfluoroalkyl acid exposures are associated with liver disease characterized by apoptosis and altered serum adipocytokines. Environ Pollut 2019; 247: 1055-63.

5. Guan CP, Luo HX, Fang HE, Zhou XZ. Global transcriptome changes of biofilm-forming staphylococcus epidermidis responding to total alkaloids of sophorea alopecuroides. Pol J Microbiol 2018; 67: 223-6.

6. Sinphitukkul K, Manotham K, Eiam-Ong S, Eiam-Ong S. Aldosterone nongenomically induces angiotensin II receptor dimerization in rat kidney: role of mineralocorticoid receptor and NADPH oxidase. Arch Med Sci 2019; 15: 1589-98.

7. Guo C, Yang L, Wan CX, et al. Anti-neuroinflammatory effect of Sophoraflavanone G from Sophora alopecuroides in LPS-activated BV2 microglia by MAPK, JAK/STAT and Nrf2/HO-1 signaling pathways. Phytomedicine 2016; 23: 1629-37.

8. Tian A, Xu T, Liu K, Zou Q, Yan X. Anti-Helicobacter pylori effect of total alkaloids of sophora alopecuroides in vivo. Chin Med J (Engl) 2014; 127: 2484-91.

9. Zhou Y, Wang H, Liang L, Zhao WC, Chen Y, Deng HZ. Total alkaloids of Sophora alopecuroides increases the expression of CD4+ CD25+ Tregs and IL-10 in rats with experimental colitis. Am J Chin Med 2010; 38: 265-77.

10. Shen XD, Ke B, Zhai Y, et al. Toll-like receptor and heme oxygenase-1 signaling in hepatic ischemia/reperfusion injury. Am J Transplant 2005; 5: 1793-800.

11. Zheng D, Li Z, Wei X, et al. Role of miR-148a in mitigating hepatic ischemia-reperfusion injury by repressing the TLR4 signaling pathway via targeting CaMKIIalpha in vivo and in vitro. Cell Physiol Biochem 2018; 49: 2060-72.

12. Nabih ES, El-Kharashi OA. Targeting HMGB1/TLR4 axis and miR-21 by rosuvastatin: role in alleviating cholestatic liver injury in a rat model of bile duct ligation. Naunyn Schmiedebergs Arch Pharmacol 2019; 392: 37-43.

13. Wigg AJ, Roberts-Thomson IC, Dymock RB, McCarthy PJ, Grose RH, Cummins AG. The role of small intestinal bacterial overgrowth, intestinal permeability, endotoxaemia, and tumour necrosis factor alpha in the pathogenesis of non-alcoholic steatohepatitis. Gut 2001; 48: 206-11.

14. Jokelainen K, Reinke LA, Nanji AA. NF-kappaB activation is associated with free radical generation and endotoxemia and precedes pathological liver injury in experimental alcoholic liver disease. Cytokine 2001; 16: 36-9.

15. Chen Y, Ma K. NLRC4 inflammasome activation regulated by TNF-alpha promotes inflammatory responses in nonalcoholic fatty liver disease. Biochem Biophys Res Commun 2019; 511: 524-30.

16. Wang C, Choi YH, Xian Z, Zheng M, Piao H, Yan G. Aloperine suppresses allergic airway inflammation through NF-kappaB, MAPK, and Nrf2/HO-1 signaling pathways in mice. Int Immunopharmacol 2018; 65: 571-9.

17. Fu X, Sun F, Wang F, et al. Aloperine protects mice against DSS-induced colitis by PP2A-mediated PI3K/ Akt/mTOR signaling suppression. Mediators Inflamm 2017; 2017: 5706152.

18. Ren D, Ma W, Guo B, Wang S. Aloperine attenuates hydrogen peroxide-induced injury via anti-apoptotic activity and suppression of the nuclear factor-kappaB signaling pathway. Exp Ther Med 2017; 13: 315-20.

19. Van Antwerp DJ, Martin SJ, Kafri T, Green DR, Verma IM. Suppression of TNF-alpha-induced apoptosis by NF-kappaB. Science 1996; 274: 787-9.

20. Wang CY, Mayo MW, Korneluk RG, Goeddel DV, Baldwin AS Jr. NF-kappaB anti-apoptosis: induction of TRAFland TRAF2 and C-IAPI and C-IAP2 to suppress caspase-8 activation. Science 1998; 281: 1680-3.

21. Chen C, Edelstein LC, Gélinas C. The Rel/NF-kappaB family directly activates expression of the apoptosis inhibitor Bcl-x(L). Mol Cell Biol 2000; 20: 2687-95. 